\title{
9Aplicação do método de gravidade, urgência e tendência (GUT) no levantamento de manifestações patológicas: estudo de caso no edifício Duque de Caxias.
}

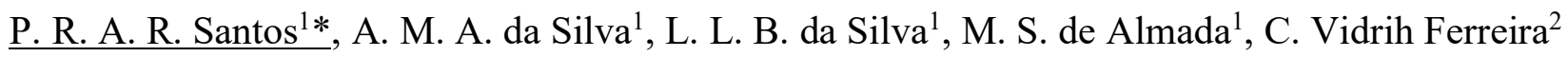 \\ *Autor de Contacto: pauloricardo.ars@gmail.com \\ ${ }^{1}$ Departamento de Engenharia Civil, UniFacema, Caxias, Maranhão, Brasil. \\ ${ }^{2}$ Instituto Vidrih, Bauru, São Paulo, Brasil.
}

\begin{abstract}
RESUMO
Os edifícios ou monumentos históricos possuem valor inestimável além da transcendência artística, cultural, religiosa, documental ou estética para a sociedade. Por se tratar de construções, estas estruturas estão sujeitas a muitas situações de degradação. Inserida nesse contexto, na cidade de Caxias - Maranhão, o Edifício Duque de Caxias, foi aplicado a Matriz de Gravidade, Urgência e Tendência (GUT) para avaliar o grau de risco das manifestações patológicas através de suas respectivas gravidades. Os resultados apontam uma lista de prioridades em ordem crescente, para as devidas prioridades em relação as manifestações patológicas de acordo com seu risco, demonstrando assim, que a Matriz GUT é uma ferramenta extremamente eficaz no auxílio à priorização da resolução de problemas patológicos nas construções.

Palavras-chave: Método GUT; Patrimônio Histórico; Edifício Duque de Caxias.
\end{abstract}

\section{Application of the gravity, urgency and tendency (GUT) method in the survey of pathological manifestations: a case study in the Duque de Caxias building.}

\begin{abstract}
Historical buildings or monuments are invaluable in addition to artistic, cultural, religious, documentary or aesthetic transcendence for society. As well as because they are constructions, these structures are subject to many degradation situations. Inserted in this context, in the city of Caxias - Maranhão, the Duque de Caxias Building, the Gravity, Urgency and Trend Matrix (GUT) was applied to assess the degree of risk of pathological manifestations through their respective severities. The results point to a list of priorities in ascending order, for the proper priorities in relation to pathological manifestations according to their risk, thus demonstrating that the GUT Matrix is an extremely effective tool in helping to prioritize the resolution of pathological problems in constructions.
\end{abstract}

Keywords: GUT method; Historical Heritage; Duque de Caxias Building.

Aplicación del método de gravedad, urgencia y tendencia (GUT) en el levantamiento de manifestaciones patológicas: estudio de caso en el edificio Duque de Caxias. 


\section{RESUMEN}

Los edificios o monumentos históricos tienen un valor incalculable además de la trascendencia artística, cultural, religiosa, documental o estética para la sociedad. Además de ser construcciones, estas estructuras están sujetas a muchas situaciones de degradación. Insertado en este contexto, en la ciudad de Caxias - Maranhão, el Edificio Duque de Caxias, se aplicó la Matriz de Gravedad, Urgencia y Tendencia (GUT) para evaluar el grado de riesgo de manifestaciones patológicas a través de sus respectivas severidades. Los resultados apuntan a una lista de prioridades en orden ascendente, para las prioridades adecuadas en relación a las manifestaciones patológicas según su riesgo, demostrando así que la Matriz GUT es una herramienta sumamente eficaz para ayudar a priorizar la resolución de problemas patológicos en edificios.

Palabras clave: método GUT; Patrimonio Histórico; Edificio Duque de Caxias.

\section{INTRODUÇÃO}

A construção civil é uma atividade que, desde os primórdios da humanidade, se manifesta como um processo de satisfazer a necessidade do ser humano. Dessa forma, construir tornou-se uma ação de realização e ao mesmo tempo de progresso para a sociedade. Essas construções foram sendo modificadas ao longo dos anos, evoluindo de edificações com estruturas robustas para estruturas cada vez mais esbeltas a partir dos avanços tecnológicos e da engenharia.

Nessa perspectiva, observa-se que os prédios históricos foram construídos a partir de uma visão mais robusta, onde as paredes possuíam dimensões duas ou até três vezes maiores em sua largura que nos dias atuais.

No entanto, no decorrer dos anos, com o desgaste natural da estrutura, tornou-se necessário analisar a vulnerabilidade estrutural e o estado de conservação, do prédio histórico aqui estudado, como ferramenta de apoio à tomada de ações em relação à segurança estrutural dessa edificação, a fim de preservar o patrimônio edificado para as gerações posteriores.

Diante da não realização de manutenções nos edifícios históricos, pretendeu-se com esta pesquisa, elencar os problemas patológicos mais comuns no edifício Duque de Caxias por meio da análise das manifestações patológicas contribuindo com informações que levem a um panorama do estado de conservação dessa edificação histórica além de estabelecer uma ordem de priorização de intervenção através do método GUT.

\subsection{Patrimônio Histórico}

O conceito de patrimônio cultural de um povo envolve as obras tanto de artistas, como, arquitetos, músicos, escritores e sábios, assim como as criações anônimas surgidas da alma popular e o conjunto de valores que dão sentido à vida.

Outro conceito importante é que a preservação do patrimônio "têm por objetivo fazer com que os bens sejam usufruídos no presente e transmitidos ao futuro da melhor maneira possível (KÜHL, 2008). A forma de se preservar o patrimônio cultural é mediante um conjunto de ações que garantam a sua permanência com os seus diversos valores e significados artísticos, paisagísticos, científicos, históricos e/ou simbólicos na vida de uma comunidade de um determinado lugar (BESSA, 2004). 
A Constituição Federal Brasileira, no artigo 216, no primeiro e segundo parágrafo, afirma que o poder Público, com a colaboração da comunidade, deve promover e proteger o patrimônio cultural brasileiro, por meio de inventários, registros, vigilância, tombamento e desapropriação, e de outras formas de acautelamento e preservação.

Essas medidas tomadas pelo Governo Federal por meio da legalização que regulamenta a conservação do Patrimônio Cultural do Brasil, outro importante meio de resguardar os bens é através da educação patrimonial, que se baseia numa ação educativa que visa difundir o conhecimento sobre o patrimônio em conjunto com a comunidade, a fim de fomentar sua valorização e preservação.

Porém, mesmo com toda essa legalização que promove e protege o patrimônio histórico, muitos desses prédios históricos encontram-se com presença de manifestações patológicas e é necessário que haja um estudo especifico apontando os tipos, causas e possíveis soluções para o tratamento das anomalias presentes na edificação e além disso a preservação do patrimônio histórico e o resgate da história, pois traz a memória o sentido pertencimento de uma cidade.

\section{MATERIAIS E MÉTODOS}

\subsection{Local do estudo}

A cidade onde foi desenvolvida a pesquisa foi Caxias-MA, a quinta mais populosa cidade do estado com população de 164.880 habitantes, área de $5.150,667 \mathrm{~km}^{2}$, o que a torna a terceira maior cidade do Maranhão. (IBGE, 2019).

A edificação em análise foi Edifício Duque de Caxias que se trata de um patrimônio histórico não tombado localizado na Praça Gonçalves Dias na cidade de Caxias-MA. O edifício trata-se de um casarão em estilo colonial, construído por volta do século XIX, o qual, segundo historiadores, teria sido onde o até então coronel Luiz Alves de Lima e Silva ficou hospedado e leu a ata de pacificação da Guerra da Balaiada. Assim, o prédio possui grande relevância histórica para a cidade. As Figuras 1 e 2 mostram a localização e a fachada do Edifício Duque de Caxias, respectivamente.

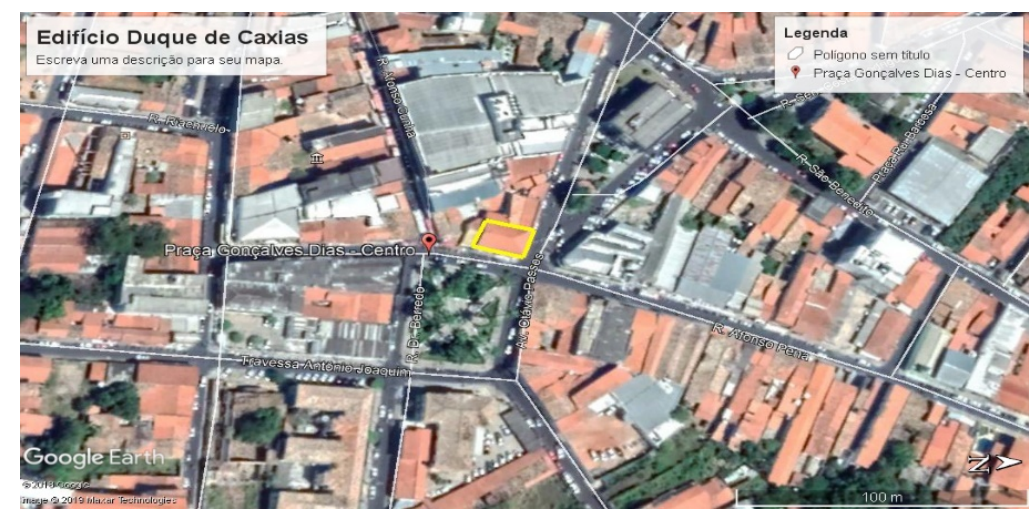

Figura 1. Imagem via satélite do Edifício Duque de Caxias. (Google Earth, 2021). 


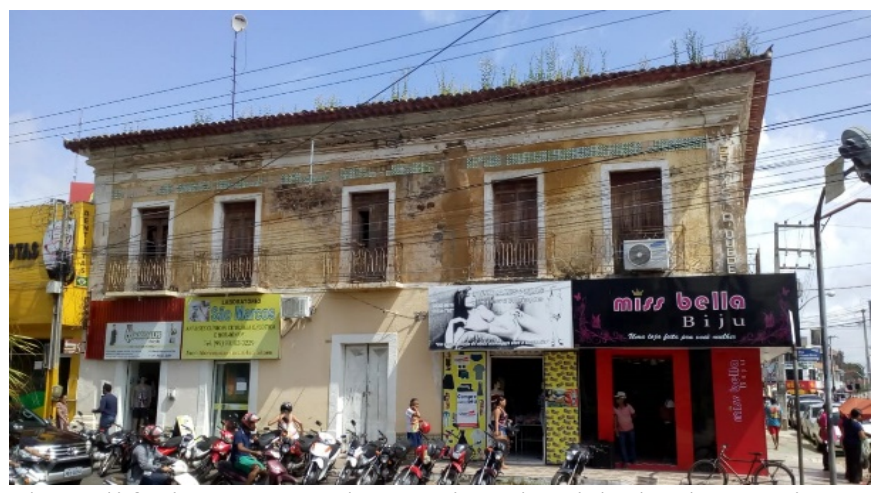

Figura 2. Fachada do Edifício Duque de Caxias da cidade de Caxias-MA (Autor, 2021).

\subsection{Tipo e abordagem da pesquisa}

O presente trabalho realizou um estudo preliminar quantitativo e qualitativo, utilizando o método GUT, fazendo análise dos tipos de patologias encontradas no local e coletados durante o estudo de caso, propondo métodos para possíveis intervenções e resoluções de problemas para cada caso especifico.

\subsection{Forma de obtenção dos dados}

\subsubsection{Método GUT}

O Método GUT tem por objetivo responder perguntas como: O que fazer primeiro? Ou por onde começar? Meireles (2001) afirma que a finalidade de responder esse tipo de pergunta é a tomada de decisão após ser analisada a proporção dos danos. Os danos serão analisados dentro de três aspectos principais que serão Gravidade, Urgência e Tendência.

O método GUT aplicado a inspeção predial possui notas que variam em escala decrescente: nota 5 para os maiores valores e 1 para os menores valores. Ao final da atribuição de notas para os problemas, seguindo os aspectos GUT, faz-se necessário produzir um número que será o resultado de toda a análise e que definirá qual o grau de prioridade daquele problema (VERZOLA et al. 2014). O cálculo é realizado conforme a eq.1 (KEPNER; TREGOE, 1991):

$$
P=G \times U \times T
$$

Após definir e listar os problemas e dar uma nota à cada um deles, é necessário somar os valores de cada um dos aspectos: Gravidade (G), Urgência(U) e Tendência(T), para então obtermos aqueles problemas que serão nossas prioridades.

O método GUT aplicado a inspeção predial fica como o demonstrado na Tabela 1:

\begin{tabular}{|c|l|c|c|}
\hline VALOR & \multicolumn{1}{|c|}{ GRAVIDADE } & URGÊNCIA & TENDÊNCIA \\
\hline \multirow{2}{*}{1} & $\begin{array}{l}\text { Nenhum risco à saúde, à integridade física dos } \\
\text { usuários, ao meio ambiente ou ao edifício. } \\
\begin{array}{l}\text { Mínima depreciação do patrimônio. Eventuais } \\
\text { trocas de componentes, nenhum } \\
\text { comprometimento do valor imobiliário. }\end{array}\end{array}$ & Nãos pressa & Não vai piorar \\
\hline
\end{tabular}




\begin{tabular}{|c|c|c|c|}
\hline 2 & $\begin{array}{l}\text { Sem risco à integridade física dos usuários, } \\
\text { sem risco ao meio ambiente, pequenos } \\
\text { incômodos estéticos ou de utilização, } \\
\text { pequenas substituições de componentes ou } \\
\text { sistemas, reparos de manutenção planejada } \\
\text { para recuperação ou prolongamento de vida } \\
\text { útil. Prejuízo financeiro pequeno. }\end{array}$ & $\begin{array}{l}\text { Pode esperar } \\
\text { um pouco }\end{array}$ & $\begin{array}{l}\text { Vai piorar a } \\
\text { longo prazo }\end{array}$ \\
\hline 3 & $\begin{array}{l}\text { Risco à saúde dos usuários, desconfortos na } \\
\text { utilização dos sistemas, deterioração passível de } \\
\text { restauração/reparo, podendo provocar perda de } \\
\text { funcionalidade com prejuízo à operação direta de } \\
\text { sistemas ou componentes. Danos ao meio } \\
\text { ambiente passíveis de reparo. Prejuízo financeiro } \\
\text { médio. }\end{array}$ & $\begin{array}{l}\text { O mais cedo } \\
\text { possível }\end{array}$ & $\begin{array}{l}\text { Vai piorar a } \\
\text { médio prazo }\end{array}$ \\
\hline 4 & $\begin{array}{l}\text { Risco de ferimentos aos usuários, danos } \\
\text { reversíveis ao meio ambiente ou ao edifício. } \\
\text { Impacto recuperável com o comprometimento } \\
\text { parcial do desempenho e funcionalidade (vida } \\
\text { útil) do sistema que afeta parcialmente a saúde } \\
\text { dos usuários ou o meio ambiente. Prejuízo } \\
\text { financeiro alto }\end{array}$ & Urgente & $\begin{array}{l}\text { Vai piorar em } \\
\text { Pouco tempo }\end{array}$ \\
\hline 5 & $\begin{array}{l}\text { Risco de morte, risco de desabamento/colapso } \\
\text { pontual ou generalizado, iminência de Incêndio, } \\
\text { impacto irrecuperável com perda excessiva do } \\
\text { desempenho funcionalidade, } \\
\text { comprometimento irrecuperável da vida útil do } \\
\text { sistema causando danos grave à saúde dos } \\
\text { usuários ou ao meio ambiente. Prejuízo } \\
\text { financeiro muito algo. }\end{array}$ & Ação imediata & $\begin{array}{l}\text { Vai piorar } \\
\text { rapidamente }\end{array}$ \\
\hline
\end{tabular}

Tabela 1. O método GUT aplicado a inspeção predial (Adaptado de Verzola et al.,2014).

\subsection{Equipamentos utilizados}

Para se obter dados que quantificaram a pesquisa, se faz necessária a utilização de alguns equipamentos básicos que auxiliem neste processo. Para efetuar o levantamento desses dados foram utilizados:

- 01 Câmera fotográfica;

- 01Trena;

- 01 Prancheta;

- 01 Régua e escalímetro;

- 02 Canetas esferográficas. 


\section{APRESENTAÇÃO E ANÁLISE DOS RESULTADOS}

Os resultados a seguir foram agrupados de acordo com as manifestações patológicas encontradas, como: descascamento de pintura; desplacamento; fissura, trinca e rachadura; mofo, bolor e fungos; das instalações hidrossanitária e elétrica e corrosão.

A Tabela 2 apresenta o resultado do levantamento realizado, que fora possível encontrar anomalias em 189 pontos distintos. Na mesma tabela também é apresentada a quantidade de cada manifestação patológica assim como sua porcentagem. A contagem foi realizada através de inspeção visual.

\begin{tabular}{|c|c|c|}
\hline TIPO & QUANTIDADE & PORCENTAGEM \\
\hline Descascamento da pintura & 37 & $19.58 \%$ \\
\hline Desplacamento & 45 & $23.81 \%$ \\
\hline Fissuras, trincas e rachaduras & 23 & $12.17 \%$ \\
\hline Mofo, bolor e fungos & 13 & $6.88 \%$ \\
\hline Hidrossanitária & 8 & $4,23 \%$ \\
\hline Corrosão & 24 & $12,70 \%$ \\
\hline Elétrica & 18 & $9,52 \%$ \\
\hline Infiltração & 21 & $11,11 \%$ \\
\hline Total & 189 & $100 \%$ \\
\hline
\end{tabular}

Tabela 2. Frequência por tipo de manifestação patológica (Autor, 2021).

Desta forma, é possível observar que as manifestações que apareceram com mais frequência na edificação estudada foram o descascamento da pintura, e com destaque também para: desplacamento, corrosão, fissuras, trincas e rachaduras.

A seguir serão expostos os registros fotográficos realizados durante o levantamento, apresentando os variados tipos de manifestações patológicas encontradas.

\subsection{Desplacamento}

No revestimento cerâmico e no piso do Edifício Duque de Caxias foram encontradas a maioria das manifestações patológicas, o desplacamento foi identificado em 45 locais diferentes como no revestimento cerâmico do piso, na fachada e alvenaria, ocupando assim a primeira posição, correspondendo a 23,81\%. A Figura 3 retrata essa situação. 


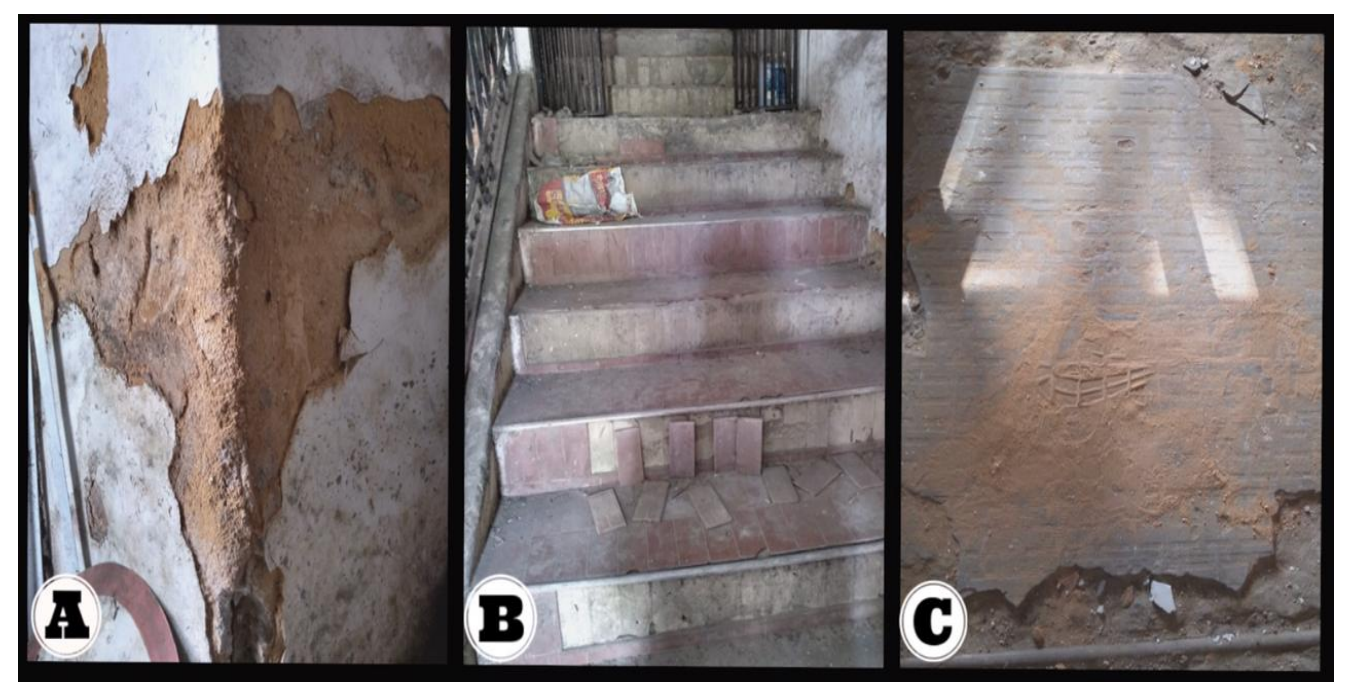

Figura 3. Desplacamento de: emboço em alvenaria (A), emboço em revestimento cerâmico da escada (B), revestimento cerâmico do piso (C) (Autor, 2021).

De acordo com Bauer (1994), as placas do revestimento de argamassa que se deslocam englobam geralmente o reboco e o emboço e a ruptura ocorrem na ligação entre essas camadas e a base. Segundo a Comunidade da Construção esses destacamentos ocorrem pela perda de aderência das placas cerâmicas do substrato, ou da argamassa colante, quando as tensões ultrapassam a capacidade de aderência das ligações entre a placa cerâmica e argamassa colante e/ou emboço.

Ou seja, neste caso esse determinado tipo de patologia pode ter ocorrido por uma falha na execução do assentamento das placas cerâmicas e ainda pode ser citado o emboço com pouca resistência além de material pulverulento entre as camadas o que gera a minoração da aderência entre as mesmas.

\subsection{Descascamento de pintura}

Logo em seguida, aparece o descascamento de pintura que pode ser identificado em 37 pontos diferentes da edificação, principalmente nas alvenarias internas além de fachada e sacada, correspondendo a um total de 19,51\%. As patologias foram identificadas na alvenaria, sacada e portais das portas. A Figura 4 mostra essas situações.

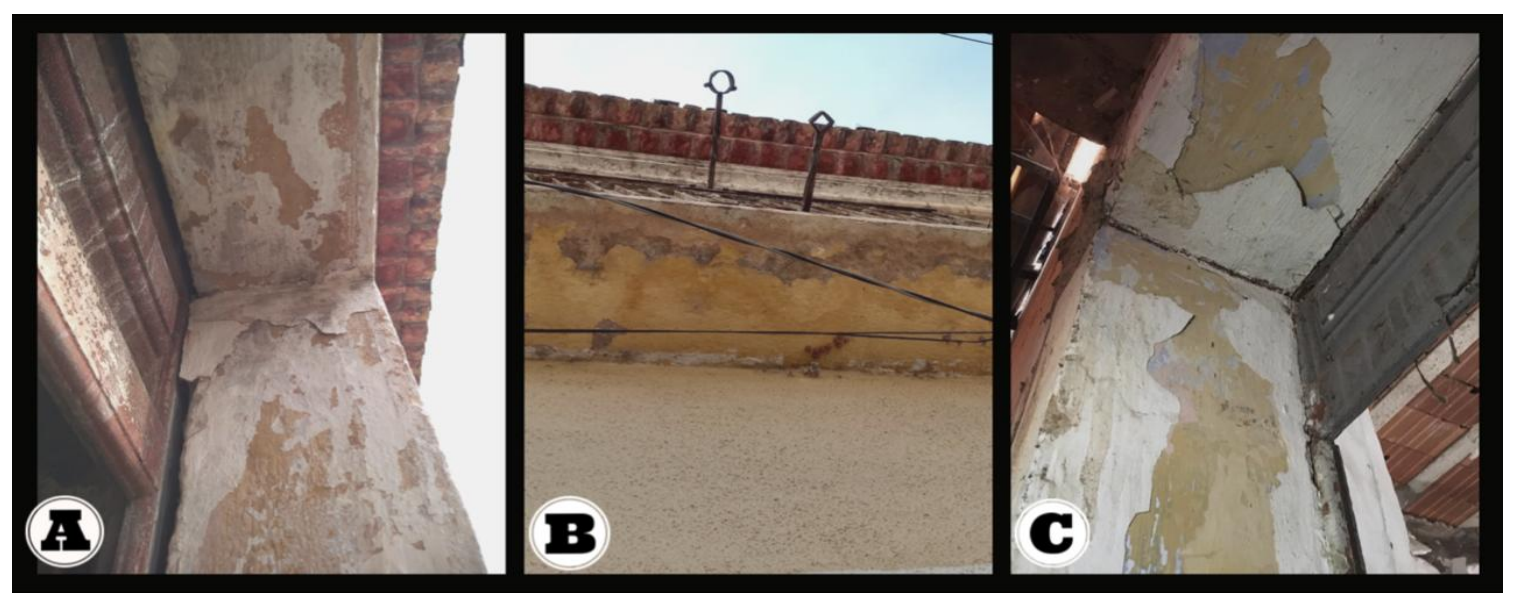

Figura 4. Descascamento em: (A) e (C) Portais das portas e (B) Sacada (Autor, 2021). 
Segundo Lima Júnior (2017), esse tipo de manifestação patológica é caracterizado pela destruição da pintura, que pode ser esfarelar e se destacar da superfície juntamente com partes do reboco. Além disso, o tempo em que a pintura foi feita sem passar por nenhum tipo de manutenção.

\subsection{Corrosão}

Adiante, aparece a corrosão foi identificado em 24 locais diferentes, correspondendo a 12,70\%. As anomalias foram detectadas no piso da escada, guarda-corpo e no pilar apresentam esse tipo de anomalia. A Figura 5 demonstra a situação.

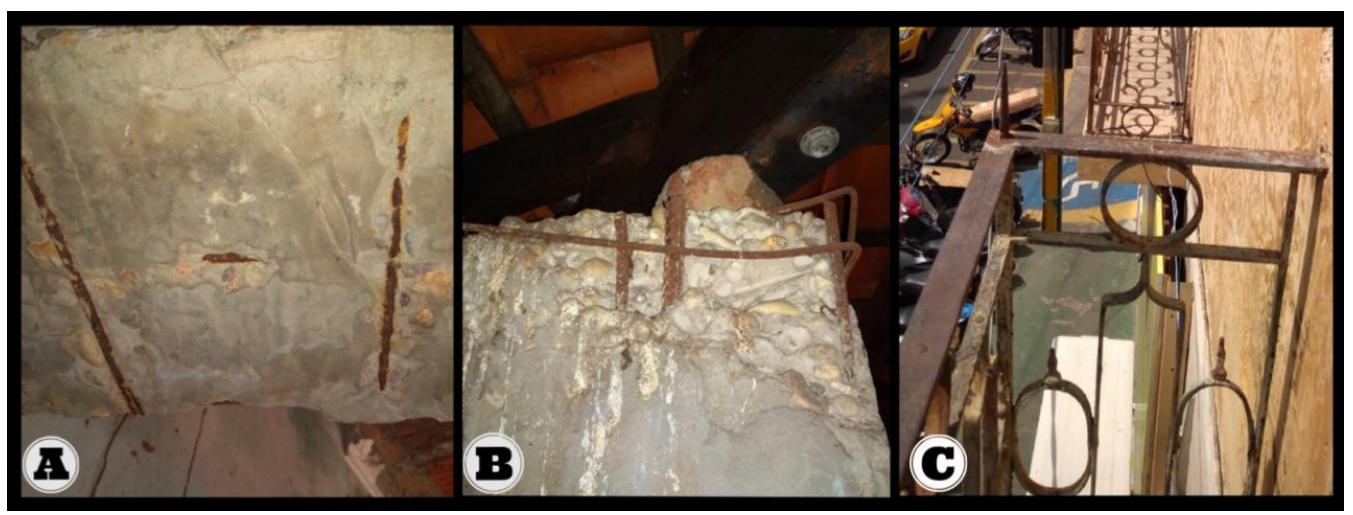

Figura 5. Corrosão em: (A) Piso da escada e (B) Pilar e (C) Guarda-corpo (Autor, 2021).

Zuthechi (2015) afirma que dentre os principais agentes que causam este tipo de patologia, se pode destacar a falta de qualidade das matérias primas utilizadas na execução, além de não haver o controle na produção do concreto. Além disso Thomaz (1989) acrescenta que as reações de corrosão, independentemente de sua natureza, produzem óxido de ferro, cujo volume é muitas vezes maior do que o original do metal. Essa expansão provoca o fissuramento e o desplacamento do concreto nas regiões próximas às armaduras. Em outros elementos metálicos a exposição excessiva ao sol bem como a umidade, agentes agressivos, tempo, e os demais possivelmente geram esse tipo de patologia.

\subsection{Infiltração}

Em seguida aparece na edificação a parte infiltração em 21 locais distintos, principalmente na fachada, correspondendo a 11,11\%. As patologias referentes a infiltração aparecem na alvenaria da fachada a Figura 6 demonstra a situação.

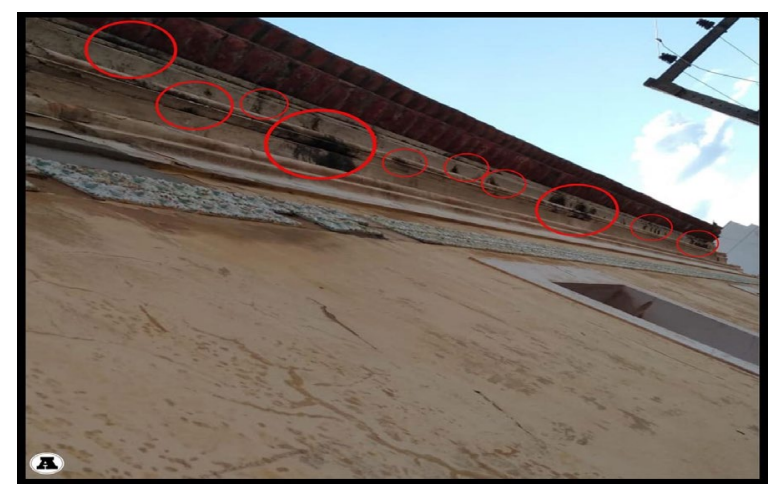

Figura 6. Infiltração em: (A) Alvenaria da Fachada (Autor, 2019). 
Segundo Nappi (1995) muitas vezes, apenas a observação visual poderá acarretar incertezas sobre a patologia, devido ao fato de vários destes sintomas não serem específicos de um dado tipo de infiltração. Pode-se afirmar que a umidade em uma edificação se manifesta de várias formas diferentes, dentre as quais podem se destacar: a umidade por capilaridade, umidade de precipitação dentre outros tipos.

Ferreira (2010) destaca que um dos maiores problemas na durabilidade dos edifícios é a umidade podendo ela ser interna ou externa. A absorção e a penetração da água da chuva nas edificações estão associadas não só à ação da chuva, mais também da combinação desta com o vento.

\subsection{Elétrica}

Logo depois, se destaca a parte elétrica que aparece em 18 locais diferentes, correspondendo a 9,52\% das patologias. A Figura 7 demonstra a situação.

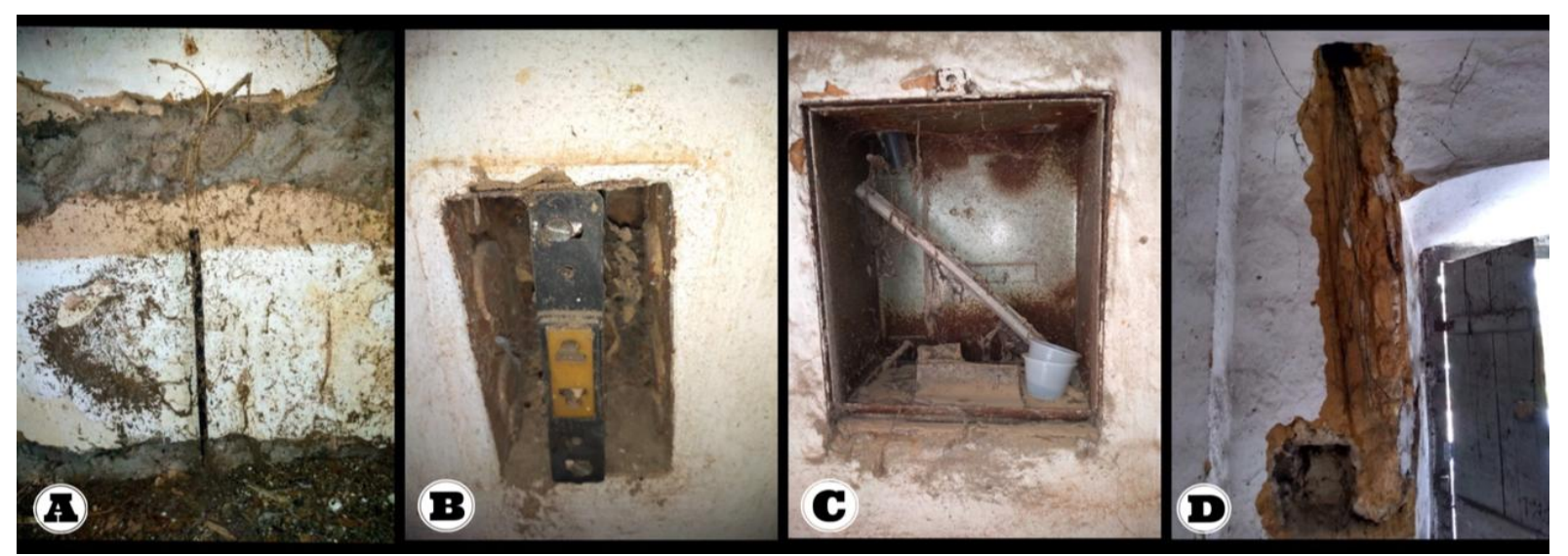

Figura 7. Deterioração em: (A) Fiação elétrica (B) Tomada (C) Caixa de distribuição. e (D) Fiação telefônica (Autor, 2021).

Segundo Nascimento (2014), procurando economizar na etapa da execução do projeto elétrico, as construtoras tem desfeito de um profissional qualificado para ter o controle da execução das instalações elétricas, sendo o caso da emenda de fiações elétricas. Pelo estado observado, além desses fatores a falta de manutenção contribui ainda mais para o estado degradado das instalações.

\subsection{Fissuras, trincas e rachaduras}

Adiante, aparecem as fissuras, trincas e rachaduras que foram identificadas em 23 locais diferentes, correspondendo a $12,17 \%$ das anomalias. Sendo que as mesmas aparecem na alvenaria interna e fachada, a Figura 8 demonstra a situação. 


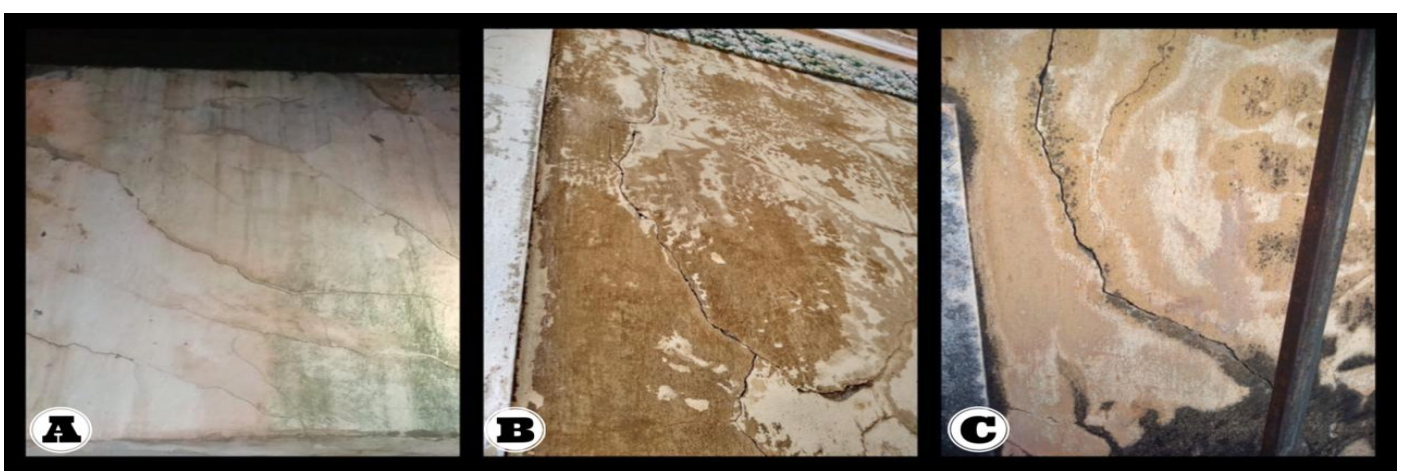

Figura 8. Fissuras, trincas e rachaduras em: (A) Alvenaria interna e (B) e (C) Alvenaria da fachada (Autor, 2021).

Thomaz (1989), destaca que dentre os vários problemas que podem revelar-se na edificação o mais importante é o problema das fissuras e trincas, devido a três aspectos: o aviso de um possível estado de perigo para a estrutura, o comprometimento do desempenho da obra em serviço (estanqueidade à água, durabilidade, isolação acústica, dentre outros) e o constrangimento psicológico que a fissuração transmite sobre os seus usuários.

Bauer (1994) afirma que, as fissuras ocorrem devidos a fatores relativos à execução do revestimento argamassado, solicitações causadas pelas ações da umidade e da temperatura (tração e retração), e principalmente por retração hidráulica da argamassa.

Observando o que foi dito nesse caso esse tipo de patologia deve ter se ocasionado pela ação da temperatura e da umidade pois todas essas fissuras ocorrem no emboço.

\subsection{Mofo, bolor e fungos}

Em penúltimo lugar aparece mofo, bolor e fungos que foi identificado em 13 locais diferentes, podendo ser destacado na alvenaria interna, na sacada e nos portais das portas correspondendo a 6,88\%. Alvenaria da sacada, alvenaria interna e a sacada, a Figura 9 demonstra a situação.

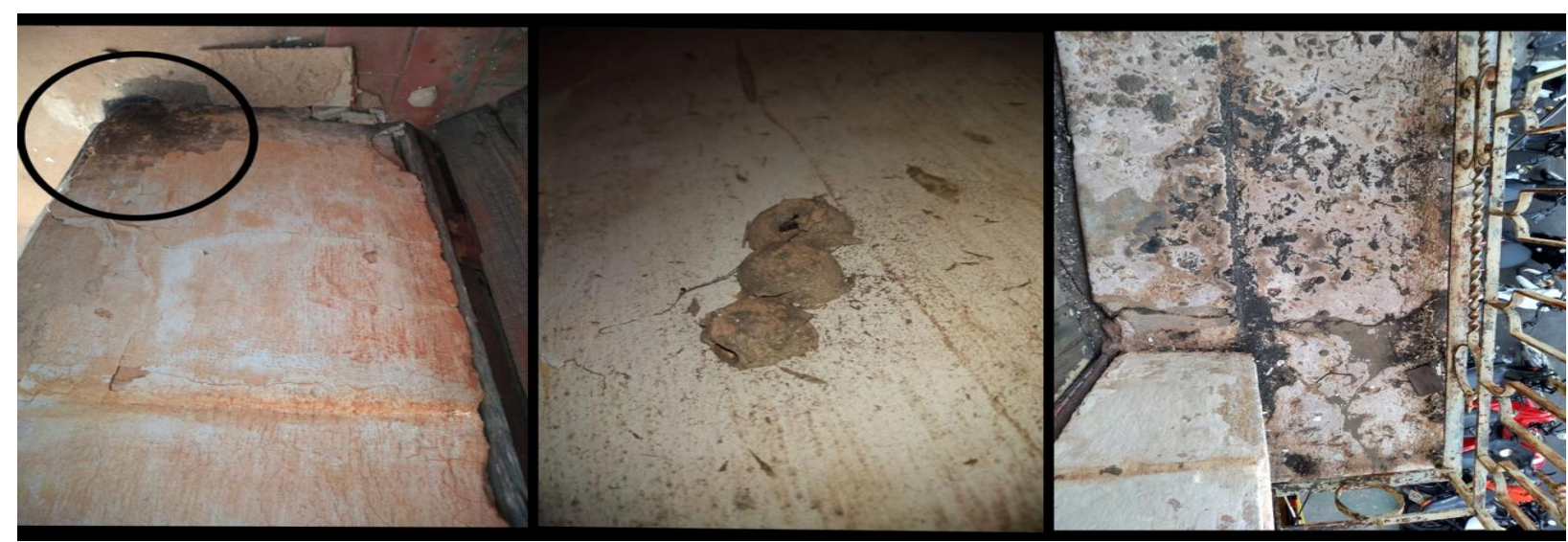

Figura 9. Bolor e fungo em: (A) Bolor em alvenaria, (B) Fungo e (C) Bolor na sacada (Autor, 2021). 
Shirakawa et al (2009) justifica que, a umidade elevada no material favorece o crescimento de fungos, uma vez que eles crescem em diferentes faixas de temperatura, necessitam de diferentes teores de umidade nos materiais. Ainda segundo os autores, a umidade do ambiente pode favorecer o aumento de umidade do material, mas somente a água absorvida por este pode ser utilizada para o desenvolvimento dos fungos.

O desenvolvimento de fungos em revestimentos, internos ou de fachada, causam o aparecimento de manchas escuras na superfície com o favorecimento da deterioração de argamassas de revestimentos e pinturas, como ilustrado na Figura 26. Além do prejuízo estético, o maior problema associado ao crescimento de fungos em ambientes internos é o desenvolvimento de alergias em indivíduos atópicos que frequentam estes ambientes (SHIRAKAWA et al, 1995).

\subsection{Hidrossanitária}

Em último lugar aparece a parte hidrossanitária que foi identificada em 9 pontos diferentes, correspondendo a 4,23\%. As patologias aparecem no vaso sanitário bem como nas tubulações do vaso sanitário e chuveiro. A Figura 10 mostra esta situação.

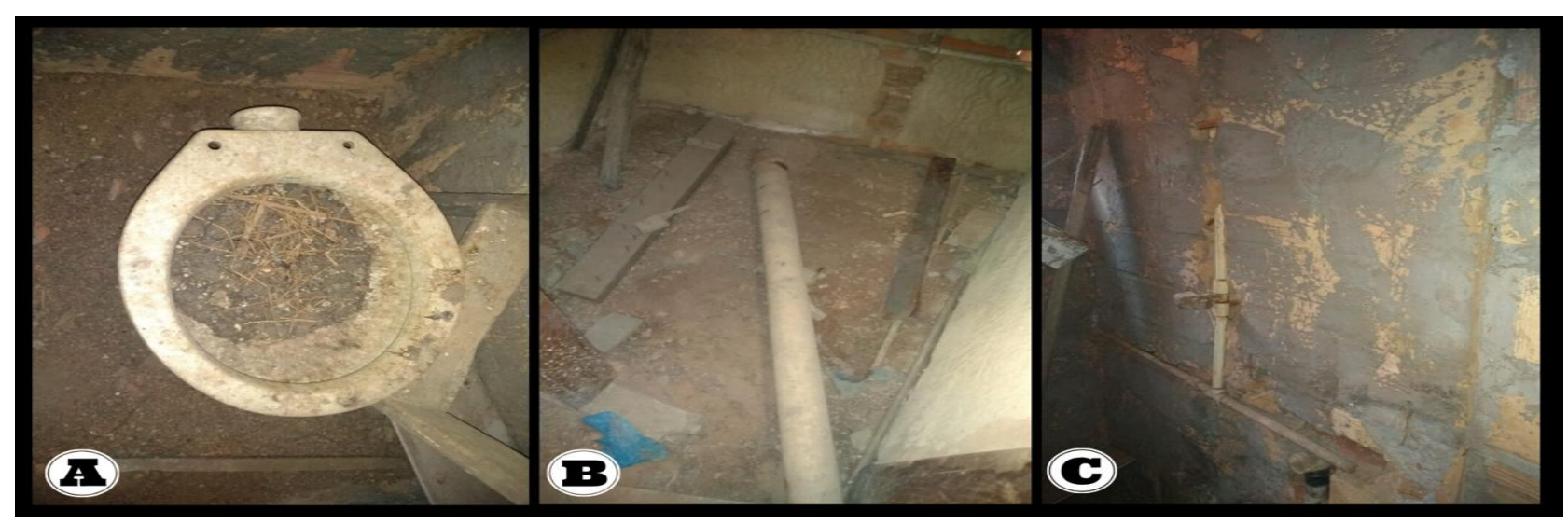

Figura 10: Na parte hidrossanitária em: (A) vaso sanitário, (B) Tubulação do Vaso sanitário e (C) Tubulação de chuveiro (Autor, 2021).

Esse determinado tipo de anomalia na parte hidrossanitária acontece pela degradação nas instalações e falta de manutenções nas mesmas. Além do mais Amorim (1989) ressalta que, depois de colocada em uso uma edificação, os sistemas prediais hidráulicos e sanitários entram em equilíbrio com os seus usuários, sendo um dos subsistemas do edifício que com eles mais se relaciona, razão pela qual o seu mau funcionamento costuma causar-lhes problemas sérios ao bem estar físico e psicológico. Esta é a etapa onde menos pesquisas acontecem, mas cujos dados são de fundamental utilidade para a melhoria da qualidade (AMORIM e FUGAZZA, 1997).

Através da Tabela 3 apresentada anteriormente, foram classificadas as manifestações patológicas identificadas no estudo de caso de acordo com as variáveis do método GUT. Os produtos obtidos através da aplicação do método expressam a análise da problemática de cada manifestação, resultando na seguinte ordem de priorização, de acordo com a Tabela 3. 


\begin{tabular}{|c|c|c|c|c|c|}
\hline $\begin{array}{c}\text { MANIFESTAÇÃO } \\
\text { PATOLÓGICA }\end{array}$ & G. & U. & T. & G.U.T. & GRAU DE PRIORIDADE \\
\hline $\begin{array}{c}\text { Descascamento de pintura } \\
\text { Desplacamento (piso } \\
\text { cerâmico e emboço) }\end{array}$ & 3 & 2 & 3 & 12 & $5^{\circ}$ \\
\hline $\begin{array}{c}\text { Fissuras, trincas e } \\
\text { rachaduras }\end{array}$ & 2 & 3 & 4 & 24 & $4^{\circ}$ \\
\hline $\begin{array}{c}\text { Mofo, bolor e fungos } \\
\text { Hidrossanitária }\end{array}$ & 2 & 2 & 2 & 8 & $3^{\circ}$ \\
\hline Corrosão & 3 & 3 & 4 & 36 & $6^{\circ}$ \\
\hline Elétrica & 3 & 3 & 3 & 27 & $5^{\circ}$ \\
\hline Infiltração & 2 & 3 & 3 & 18 & $2^{\circ}$ \\
\hline
\end{tabular}

Tabela 3. Matriz de Aplicação pelo método G.U.T. (Autor, 2021).

Os resultados obtidos após aplicação do método de forma a esclarecer, foram dispostos na Tabela 4 de forma crescente o grau de prioridade em suas resoluções, juntando as manifestações que apresentam a mesma pontuação final.

\begin{tabular}{|c|c|}
\hline GRAU DE PRIORIZAÇÃO & MANIFESTAÇÃO PATOLÓGICA \\
\hline $1^{\circ}$ & Corrosão \\
\hline $2^{\circ}$ & Elétrica \\
\hline $3^{\circ}$ & Fissuras, trincas e rachaduras \\
\hline \multirow{2}{*}{$4^{\circ}$} & Infiltração \\
\cline { 2 - 2 } & Desplacamento \\
\hline \multirow{2}{*}{$5^{\circ}$} & Hidrossanitária \\
\cline { 2 - 2 } & Descascamento de Pintura \\
\hline \multirow{2}{*}{$6^{\circ}$} & Mofo, Bolor e fungos \\
\hline
\end{tabular}

Tabela 4. Disposição da prioridade para reparo das patologias existentes (Autor, 2021).

Em referência a aplicação do método GUT percebe-se que a corrosão, que na maioria das vezes são provocadas por causa da oxidação da armadura, estão próximas no grau de prioridade, fazendo com que o método tenha significância exata. Nota-se também que o desplacamento, mesmo aparecendo em maior quantidade, não é prioridade para ser solucionado tão logo. 


\section{CONCLUSÕES}

O presente trabalho proporcionou identificar as principais manifestações patológicas presentes no Edifício Duque de Caxias em Caxias-MA, patrimônio histórico com cerca de 100 anos. As ocorrências que mais se destacaram foram: desplacamento com $23,81 \%$, descascamento de pintura com 19,58\%, fissuras, trincas e rachaduras com $12,70 \%$, e mofo, bolor e fungos com $12,17 \%$.

Diante de tudo que foi exposto, é notório que o principal motivo para a ocorrência de degradação em um prédio é o fator de manutenção, o que gera uma série de manifestações patológicas, como por outros, que estão ligados a construção e alterações no edifício realizadas no decorrer dos anos. É importante frisar que uma reforma do local se faz necessária, devido a condição para preservação e condições de uso, principalmente pela importância da história do local para a cidade de Caxias. No tocante, a aplicação do Método GUT se fez eficiente pelo fato da priorização realizada, guiar a realização de manutenção no edifício inspecionado, de acordo com as manifestações patológicas localizadas no topo da lista. Tendo em vista as observações feitas, a ferramenta GUT pôde ser aplicada como facilitadora no planejamento das atividades de manutenção da edificação com base nos resultados e na avaliação proposta.

Ademais, o presente trabalho pretende agregar para um plano de manutenção e além disso um plano de conservação das edificações, por meio da proposição de um método de inspeção predial, tomando como base as normas e instruções técnicas, e métodos presentes na bibliografia.

\section{REFERENCIAS}

AMORIM, S. V. Instalações prediais hidráulico-sanitárias: desempenho e normalização. São Carlos, 1989. 168 p. Dissertação (Mestrado). Escola de Engenharia de São Carlos, Universidade de São Paulo, 1989.

AMORIM, S. V.; FUGAZZA, A. E. (colaborador). Incidência de falhas em sistemas prediais: estudo de caso. In: CONGRESSO IBEROAMERICANO DE PATOLOGIA DAS CONSTRUÇÕES, IV; CONGRESSO DE CONTROLE DE QUALIDADE, VI, 21-24 out. 1997. Porto Alegre. Anais. 7 p.

BAUER, L. A. F. Materiais de construção. $5^{\mathrm{a}}$ ed. Rio de Janeiro: LTC, 1994. v.2.

BESSA, A. S. M. Preservação do Patrimônio Cultural: nossas casas e cidades, uma herança para o futuro. Belo Horizonte: Crea - MG, 2004.

FERREIRA, B. B. D. Tipificação de patologias em revestimentos argamassados. Dissertação (mestrado) - Universidade Federal de Minas Gerais, Escola de Engenharia, Belo Horizonte, 2010. GOMIDE, T. L. F. NETO, J. C. P. F. GULLO, M. A. Engenharia Diagnóstica em edificações. PINI: São Paulo, 2009.

GOOGLE EARTH. Edificio Duque de Caxias de Caxias-MA, Brasil. Disponível em: $<$ https://earth.app.goo.gl/?apn=com.google.earth\&isi $=293622097 \&$ ius $=$ googleearth\&link $=\mathrm{https} \%$ 3a\%2f\%2fearth.google.com\%2fweb\%2f\%40-4.86292038,-

43.3610336,70.99411008a,107.7805189d,35y,-154.0920578h,23.80237102t,-

0r\%2fdata\%3dChYaFAoML2cvMXEydzdkYnFjGAEgASgC >. Acesso em: 07 de julho de 2017. IBGE - Instituto Brasileiro de Geografia e Estatística. Censo Demográfico 2019.

KEPNER, C., \& TREGOE, B. (1991). O Novo Administrador Racional. São Paulo: Makron Books. KÜHL, Beatriz Mugayar. Arquitetura do Ferro e Arquitetura Ferroviária em São Paulo. São Paulo: Ateliê Editorial/Fapesp/Secretaria da Cultura, 1998. 
LIMA JÚNIOR, W. J. Análise das manifestações patológicas comumente encontradas nos revestimentos da Universidade Federal de Alagoas, Campus do Sertão. 2017. Trabalho de conclusão de curso (graduação em engenharia civil), UFAL, Delmiro Gouveia.

MEIRELES, M. Ferramentas administrativas para identificar, observas e analisar problemas. 1. ed. São Paulo: Art \& Ciência, 2001.

NAPPI, Sérgio C. B. Umidade em paredes. In: "Congresso Técnico-Científico de Engenharia Civil”. Anais. Universidade Federal de Santa Catarina. Florianópolis: 1995. v 4.

NASCIMENTO, Rogério Edison. Patologia das construções devido ao tempo de uso: ênfase em instalações. Disponível em: Acesso em: 22 ago. 2019. Curitiba, 2014.

SHIRAKAWA, M., A.; CINCOTTO, M. A.; GAMBALE, V. Influência do crescimento de fungos na carbonatação de argamassas. In: Simpósio Brasileiro de Tecnologia de Argamassas, VIII, In: Anais, ANTAC, Curitiba, 2009.

THOMAZ, E. Trincas em Edifícios - Causas, prevenção e recuperação. São Paulo: Pini,1989.

VERZOLA, S. N.; MARCHIORI, F.F.; ARAGON, J.O. Proposta de lista de verificação para inspeção predial $x$ urgência das manutenções. XV Encontro Nacional de Tecnologia do ambiente Construído - ENTAC. Maceió, 2014.

ZUCHETTI, P. A. B. Patologias da construção civil: investigação patológica em edifício corporativo de administração pública no Vale do Taquari/RS.2015. Trabalho de conclusão de curso (graduação em engenharia civil), UNIVATES, João Batista Gravina. 